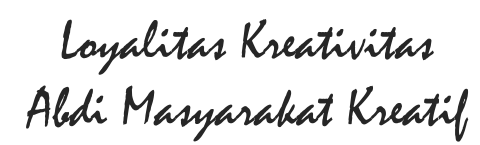

Loyalitas Kreativitas

Aldi Masyarakat Kreatif
P-ISSN 2722-2101, E-ISSN 2722-4201

Program Studi Ekonomi Manajemen Universitas Pamulang Jurnal LOKABMAS Kreatif Vol. 01, No. 02, Hal. 56-61

Email:jurnalkreatif.manajemen@gmail.com

\title{
MEMBANGUN KARAKTERISTIK PESERTA DIDIK DI ERA REVOLUSI INDUSTRI 4.0 YANG DILANDASI DENGAN IMTAQ
}

\author{
Agrasadya, Ading Sunarto, Putri Nilam Kencana, Baliyah Munadjat, Mita Sicillia \\ Dosen Ekonomi Fakultas Ekonomi Universitas Pamulang
}

Email : $\frac{\text { dosen01866@unpam.ac.id }}{\text { dosen02162@unpam.ac.id }, \text { dosen2153@unpam.ac.id }}, \underline{\text { dosen01877@ @unpam.ac.id }}$,

\begin{abstract}
ABSTRAK
Tujuan dari kegiatan pengabdian kepada masyarakat di Yayasan Pembangunan Masyarakat Sejahtera (YPMS) Cabang Kedaung Pamulang Tangerang Selatan ini untuk memberikan pengetahuan dan wawasan tentang makna dan pemahaman tentang pembangunan karakteristik peserta didik di era revolusi industry 4.0 yang dilandasi dengan imtaq.

Metode pelaksanaan pengabdian ini dilakukan dalam beberapa kegiatan yaitu tahap survei yaitu sosialisasi dilakukan dengan menyusun berbagai hal yang akan disampaikan pada saat kegiatan pengabdian yang akan dilakukan yang meliputi: penyusunan materi yang akan diberikan, penyusunan jadwal pemberian materi, pembagian tugas tim pengabdian dan survei ke lokasi pengabdian. Tahap sosialisasi yaitu sebelum kegiatan pengabdian dilaksanakan terlebih dahulu dilakukan tahap sosialisasi yaitu melakukan silaturahmi dengan kepala sekolah, menyampaikan maksud dan tujuan pengabdian ini. Pada tahap ini juga dilakukan jalinan kerjasama dan menentukan jadwal kegiatan pengabdian. Tim pelaksana kegiatan pengabdian pada masyarakat adalah dosen Fakultas Ekonomi jurusan manajemen sebanyak 5 orang. Tim pengabdian memberikan materi penyuluhan membangun karakteristik peserta didik di era revolusi industry 4.0 yang dilandasi dengan imtaq, di Yayasan Pembangunan Masyarakat Sejahtera (YPMS) Kedaung.

Hasil pengabdian masyarakat yang diperoleh adalah bertambahnya keilmuan bagi Para Peserta (Siswa/siswi) Yayasan Pembangunan Masyarakat Sejahtera (YPMS) Kedaung agar mereka memiliki karakteristik yang dapat meningkatkan keilmuan dan ketakwaan di era revolusi industry 4.0 yang dilandasi dengan imtaq. Ilmu yang diperoleh pada Pengabdian Masyarakat kali ini diharapkan mampu memberikan semangat baru bagi kita dalam menyampaikan materi dan motivasi serta berkontribusi bagi generasi muda, baik dilingkungan sekolah, kampus dan keluarga.
\end{abstract}

\section{Kata Kunci: Hiasan, Perca, Usaha}

\section{ABSTRAC}

The purpose of community service activities at the Prosperous Community Development Foundation (YPMS), Kedaung Pamulang Branch, South Tangerang, is to provide knowledge and insights about the meaning and understanding of the development of learner characteristics in the era of the industrial revolution 4.0 which is based on imtaq.

The method of implementing this service is carried out in a number of activities, namely the survey stage, namely the socialization carried out by arranging various things to be delivered at the time of service activities that will be carried out which include: preparation of material to be given, preparation of material delivery schedule, division of tasks of the service team and survey to the location devotion. The socialization phase is before the community service activities are carried out first, the socialization phase is to make a friendship with the school principal, conveying the aims and objectives of this service. At this stage cooperation is also carried out and determine the schedule of service activities. The implementing team of community service activities are 5 people from the Faculty 


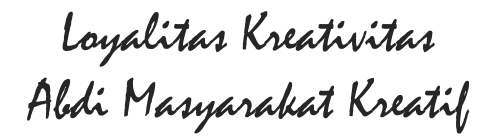

P-ISSN 2722-2101, E-ISSN 2722-4201

Program Studi Ekonomi Manajemen Universitas Pamulang Jurnal LOKABMAS Kreatif Vol. 01, No. 02, Hal. 56-61

Email:jurnalkreatif.manajemen@gmail.com

of Economics majoring in management. The dedication team provides counseling materials to build the characteristics of students in the era of the industrial revolution 4.0 based on IMTAQ, at the Kedaung Prosperous Community Development Foundation (YPMS).

The results of community service obtained are increased knowledge for the Participants (Students) of the Kedaung Prosperous Community Development Foundation (YPMS) so that they have characteristics that can enhance scholarship and piety in the era of the industrial revolution 4.0 which is based on imtaq. The knowledge gained at Community Service this time is expected to be able to provide new enthusiasm for us in conveying material and motivation as well as contributing to the younger generation, both within the school, campus and family environments.

\section{Keywords: Counseling, Creative, Innovative, Imtaq}

\section{PENDAHULUAN}

Berangkat dari krisis multidimensional yang dialami oleh bangsa ini sudah sepatutnya kita mempersiapkan generasi tersebut sebagai pelanjut dari estapet kepemimpinan di negeri ini. Dampak dari krisis ini tidak sedikit generasi kita ini, yang mengalami nasib kurang baik, sekolah terputus, dan hidup pas-pasan Pada tahun 1989 Kami resmi membentuk "YAYASAN PEMBANGUNAN MASYARAKAT SEJAHTERA" yang disingkat YPMS. Sebuah Panti Asuhan yang bukan saja menjadi tempat anak anak berkumpul dan mengkaji ilmu Agama, namun anak anak juga dididik dengan pendidikan formal dengan tetap tidak meninggalkan kegiatan utama, yaitu beribadah dan belajar / mengaji. Kami sadar, untuk mempersiapkan generasi penerus yang beribadah, handal, dan tangguh tidaklah mudah. Karena sebagaimana kita ketahui bersama tingkat kehidupan bagi setiap orang pasti berbeda. Biaya hidup yang besar, menyebabkan keluarga menentukan pilihan skala prioritas dalam penentuan pembiayaan kehidupan, bertahan hidup, menjadi prioritas pembiyaan, sementara pendidikan menjadi hal yang dinomordua-kan dalam pembiayaan hidup. Dibutuhkan pengorbanan moril dan materiil dari Kaum Muslimin yang terpanggil jiwanya untuk memikul tanggung jawab bersama. Menyikapi hal tersebut di atas, mudah-mudahan kitalah orang yang dapat menjadi tumpuan mereka. Inilah tugas mulia yang menantang kita, merupakan wujud tanggung jawab sebagai seorang yang mempunyai tugas menyematkan generasi masa depan. Sebagai Panti / Lembaga yang menyantuni Kaum Dluafa, YPMS mengajak Kaum Muslimin dan Muslimat untuk mewujudkan cita-cita luhur membentuk generasi yang handal dan siap menjawab tantangan zaman. Dan menciptakan sebuah panti yang baik dan memenuhi standar kelayakan, maka salah satu syarat yang diperlukan adalah terpenuhinya kebutuhan dasar (makan, pakaian, pendidikan dan kesehatan) anak asuhnya. Saat ini (th 2019), YPMS menampung 199 (seratus sembilah puluh sembilan) balita 3, TK 1 , anak asuh 131 dan 35 (tiga puluh Lima) pengurus.

Kegiatan Kami lebih memfokuskan pada terpenuhinya pendidikan mereka sebagai modal masa depan yang sangat berarti dan bermanfaat, sebab pendidikanlah yang dianggap sangat berpengaruh dalam perubahan masa depan. Permasalahan saat ini yaitu meningkatnya biaya kebutuhan pokok Panti Asuhan dan biaya pendidikan peserta didik. Di era industri 4.0 perkembangan teknologi sangat masif dan cepat sampai tidak bisa diprediksi dampaknya. Dampak yang diakibatkan di era industri 4.0 berpengaruh terhadap dunia kerja dan pendidikan. Selain itu, dampak teknologi digital ini juga ikut mewarnai pada aspek pola kerja, waktu kerja ,cara kerja, dan segala aspek jenis pekerjaan akan berubah sebagai akibat dari adanya revolusi industri 4.0. Demikian pula pada dunia pendidikan, niscaya berubah bergerak maju sebagai akibat dari dampak revolusi industri 4.0. Maka pendidikan tidak bisa tinggal diam begitu saja dalam menyikapi bentuk perubahan yang begitu cepat dan mengglobal. Pendidikan mesti terlibat dalam arus globalisasi dengan melakukan inovasiinovasi. Hal ini, bertujuan untuk memberikan metode dan strategi baru yang relevan terhadap peserta didik dalam proses pembelajaran di dalam kelas. Sedangkan dalam 


\section{Loyalitas Kreativitas \\ Aldi Masyarakat Kreatif}

P-ISSN 2722-2101, E-ISSN 2722-4201

Program Studi Ekonomi Manajemen Universitas Pamulang Jurnal LOKABMAS Kreatif Vol. 01, No. 02, Hal. 56-61

Email:jurnalkreatif.manajemen@gmail.com sistem pembelajarannya, seorang guru harus bisa memahami kebutuhan peserta didik, tidak hanya membekali dengan kekayaan teknologi, melainkan juga membekali dalam hal spritualitas. Mengingat nilai-nilai etika, kebijaksaan,dan budi pekerti tidak dapat diajarkan oleh mesin. Oleh karena itu, nilainilai spiritualitas sangat penting untuk membentengi peserta didik dari dampak teknologi yang begitu masif perkembangannya. Dengan demikian, peran guru di lembaga sekolah sangat urgent untuk memberikan materi yang tepat tehadap peserta didik. Agar peserta didik tidak hanya memiliki kecakapan dalam bidang ilmu teknologi, tetapi juga memiliki nilai-nilai karakter yang berlandaskan pada etika, moral, dan akhlak. Karena pembentukan karakter merupakan salah satu tujuan yang ingin dicapai dalam pelaksanaan pendidikan nasional.

Dalam konteks ini, agar pembentukan karakter peserta didik dapat terealisasi sesuai dengan tujuan awal pendidikan nasional yang berorientasi pada nilai-nilai luhur bangsa dan negara. Maka dibutuhkan penguatan dan pengembangan nilai-nilai kehidupan terhadap peserta didik. Pertama, memfasilitasi penguatan dan pengembangan nilai-nilai relegius dan cinta tanah air terhadap peserta didik. Penguatan dan pengembangan ini, memiliki arti bahwa pendidikan dalam konteks sekolah tidak hanya berorientasi pada proses dogmatisasi nilai terhadap peserta didik, tetapi sebuah proses yang membentuk peserta didik untuk memahami dan merefleksikan tentang bagaimana suatu nilai menjadi penting untuk diimplementasikan dalam perilaku keseharian setiap individu. Selain itu, penguatan juga mengandung arti bahwa proses pendidikan merupakan proses pembiasaan hidup. Karena melalui proses pembiasaan ini, peserta didik akan memiliki hubungan sinergis antara penguatan perilaku melalui pembiasaan di lingkungan sekolah, rumah, dan masyarakat. Kedua, mengoreksi perilaku peserta didik yang tidak sesuai dengan nilai-nilai yang dikembangkan oleh sekolah. Tujuan ini memiliki makna, bahwa sasaran pendidikan karakter adalah upaya meluruskan berbagai perilaku peserta didik yang negatif untuk menjadi perilaku yang positif. Proses pelurusan ini juga sebagai proses pengkoreksian yang dimaknai proses pedagogis yang dinamistransformatif, bukan suatu pemaksaan dan doktrinisasi yang tidak mendidik.

Oleh karena itu, agar proses koreksi ini tidak sia-sia, maka harus dibarengi dengan keteladanan baik di lingkungan sekolah, rumah, dan masyarakat. Ketiga, membangun koneksi yang harmoni dengan keluarga dan masyarakat dalam memerankan tanggungjawab pendidikan karakter secara bersama. Tujuan ini berarti, bahwa proses pendidikan karakter di lingkungan sekolah harus dihubungkan dengan proses pendidikan di lingkungan keluarga. Dan apabila proses pendidikan karakter hanya di lakukan di lingkungan sekolah, tanpa dilakukan di lingkungan keluarga serta masyarakat. Maka, pencapaian berbagai karakter yang diinginkan akan sulit terwujudkan. Sebab, penguatan perilaku merupakan sesuatu yang bersifat holistik (menyeluruh), bukan cuplikan (parsial) dari rentangan waktu yang dimiliki peserta didik. Dengan demikian, apabila nilai-nilai penguatan dan pengembangan pendidikan karakter di era revolusi industri 4.0 di atas bisa diaplikasikan dengan baik. Maka harapannya pendidikan karakter bisa membentuk bangsa yang tangguh, berakhlak mulia, bermoral, bergotongroyong, berjiwa patriotik, dan berorientasi pada ilmu pengetahuan dan teknologi yang semuanya dijiwai oleh iman dan takwa kepada Tuhan Yang Mahaesa berdasarkan Pancasila.

\section{RUMUSAN MASALAH}

Dengan mempertimbangkan latar belakang yang telah dijelaskan diatas kami berinisiatif untuk membentuk pengabdian masyarakat bagi siswa dan siswi yang berada di Yayasan Pembangunan Masyarakat Sejahtera Kedaung Pamulang khususnya dalam program penyuluhan pelatihan dan pendidikan berkarakter agar para siswa memiliki wawasan dan pengetahuan serta keterampilan dalam menghadapi revolusi industry 4.0. Dari identifikasi masalah tersebut, dapat dirumuskan masalah sebagai berikut:

1. Bagaimana cara meningkatkan pengetahuan dan pemahaman siswa di Yayasan 


\section{Loyalitas Kreativitas \\ Aldi Masyarakat Kreatif}

P-ISSN 2722-2101, E-ISSN 2722-4201

Program Studi Ekonomi Manajemen Universitas Pamulang Jurnal LOKABMAS Kreatif Vol. 01, No. 02, Hal. 56-61

Email:jurnalkreatif.manajemen@gmail.com
Pembangunan Masyarakat Sejahtera Kedaung Pamulang tentang persaingan ekonomi global?

2. Bagaimana menyadarkan siswa akan peran penting kewirausahaan bagi perekonomian bangsa di masa depan?

3. Bagaimana meningkatkan jiwa kewirausahaan siswa di Yayasan Pembangunan Masyarakat Sejahtera Kedaung Pamulang?

4. Bagaimana membuat rencana usaha kreatif bagi siswa di Yayasan Pembangunan Masyarakat Sejahtera Kedaung Pamulang?

\section{TUJUAN PELAKSANAAN}

1. Memberikan pengetahuan dan wawasan kepada peserta Yayasan Pembangunan Masyarakat Sejahtera Kedaung Pamulang mengenai persaingan ekonomi global.

2. Memberikan pengetahuan kepada peserta Yayasan Pembangunan Masyarakat Sejahtera Kedaung Pamulang mengenai pern penting kewirausahaan.

\section{TINJAUAN PUSTAKA}

\section{Kreatif, Inovatif, Kesuksesan}

Kreativitas merupakan kemampuan mengembangkan ide dan cara-cara baru dalam memecahkan masalah dan menemukan peluang dan ide untuk menciptakan sesuatu yang baru \& berbeda, atau istilah lain "Thinking New Things". Kreativitas menurut Munandar dalam Sunaryo (2002), adalah kemampuan untuk mengkombinasikan, memecahkan atau menjawab masalah, dan cerminan kemampuan operasional anak kreatif.

Inovasi merupakan kemampuan menerapkan kreatifitas dalam rangka memecahkan masalah dan menemukan peluang, atau suatu gagasan \& ide-ide yang berguna dan dapat dijual, atau dalam istilah lain yaitu "Doing New Things". Sedangkan menurut UU Nomor 19 Tahun 2002, inovasi adalah kegiatan penelitian, pengembangan, dan atau pun perekayasaan yang dilakukan dengan tujuan melakukan pengembangan penerapan praktis nilai dan konteks ilmu pengetahuan dan teknologi yang sudah ada ke dalam produk atau pun proses produksinya.
Definisi sukses adalah berhasil, beruntung. Yaitu tercapainya suatu tujuan, harapan dan mimpi. Sukses adalah mendapatkan apa yang diinginkan. Kebahagiaan adalah menginginkan apa yang didapatkan. Kreatif memiliki daya cipta atau berdaya cipta, sementara inovatif berdaya perubahan atau pembaruan. Kreatif menciptakan sesuatu yang berbeda, sementara inovatif menciptakan sesuatu yang belum ada.

Untuk mengembangkan cara berfikir kreatif dan inovatif, dapat dilakukan dengan cara : memiliki mimpi \& imajinasi, melatih diri untuk berfikir berbeda (out of the box) dari yang lain, mendengarkan orang lain dan terus belajar serta berlatih. Kewirausahaan (entrepreneurship) muncul apabila seseorang individu berani mengembangkan usaha-usaha dan ide-ide barunya. Proses kewirausahaan meliputi semua fungsi, aktivitas dan tindakan yang berhubungan dengan perolehan peluang dan penciptaan organisasi usaha (Suryana, 2001).

\section{HASIL DAN PEMBAHASAN}

Kegiatan Pengabdian Masyarakat Universitas Pamulang yang dilakukan oleh dosen-dosen program studi Manajemen telah berjalan dengan lancar dan mendapat sambutan hangat dari tempat pelaksanaan kegiatan ini yaitu di Yayasan Pembangunan Masyarakat Sejahtera Kedaung Pamulang

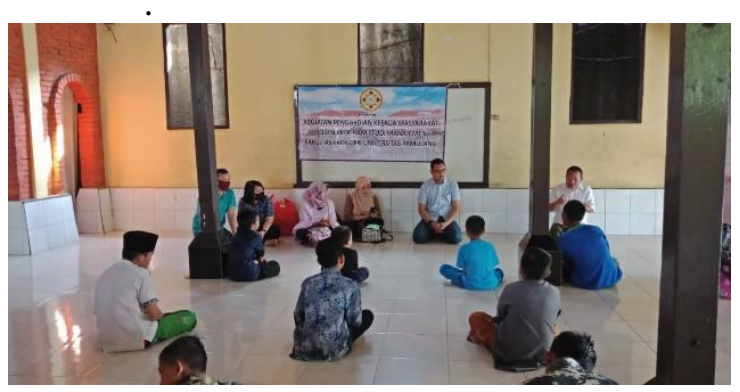

Peserta diberikan pengetahuan tentang arti sebuah kreatifitas, inovatif dan kesuksesan serta tentang perekonomian global serta peran pemuda dalam membangun perekonomian Indonesia di masa depan. Peserta juga diberikan motivasi agar memiliki kesadaran akan pentingnya kewirausahaan bagi ekonomi Indonesia, sehingga jiwa wirausaha setiap 


\section{Loyalitas Kreativitas \\ Aldi Masyarakat Kreatif}

P-ISSN 2722-2101, E-ISSN 2722-4201

Program Studi Ekonomi Manajemen Universitas Pamulang Jurnal LOKABMAS Kreatif Vol. 01, No. 02, Hal. 56-61

Email:jurnalkreatif.manajemen@gmail.com peserta dapat meningkat dan memiliki keinginan untuk mendirikan dan membangun usaha kreatif. Langkah pertama diselenggarakan selama 1 jam.

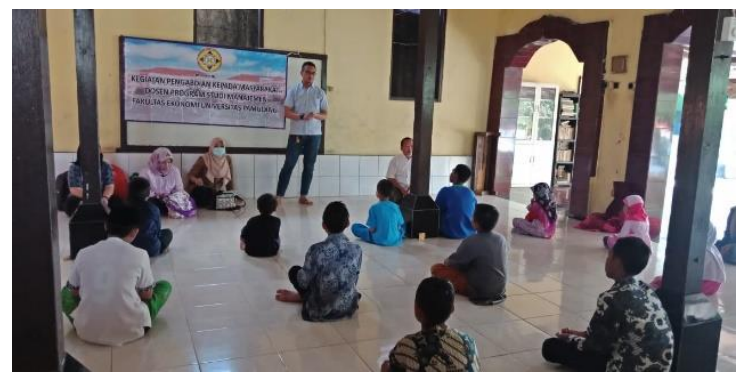

Peserta PKM diberikan materi tentang perencanaan usaha kreatif dalam menghadapi era revolusi industry 4.0 dengan pemanfaatan peluang secara kreatif dan inovatif dari barang bekas, barang yang disediakan oleh alam dan kejadian/peristiwa di sekitarnya, mulai dari menganalisis peluang usaha sampai dengan penentuan produk, pengelolaan keuangan, serta pemasarannya. Langkah kedua diselenggarakan selama 2 jam.

\section{KESIMPULAN DAN SARAN Kesimpulan}

Berdasarkan hasil pelaksanaan kegiatan PKM yang telah dilakukan, dapat diambil kesimpulan bahwa peserta dapat meningkatkan pengetahuan sekaligus sebagai stimulasi agar peserta atau siswa lebih kreatif dalam membuat materi dan tugas pelajaran di sekolah.

Dalam keterbatasan waktu dan pengelolaan, tim menyadari waktu dan biaya untuk penyuluhan ini masih harus ditingkatkan untuk kegiatan PKM ini. Rencana tahapan berikutnya yang menurut tim gariskan diantaranya adalah sebagai berikut :

1. Penyuluhan terapan dan refleksi keterampilan yang sudah diberikan perlu untuk dimodifikasi dan ditingkatkan.

2. Produk-produk dari pelatihan yang sudah diberikan dan dibuatkan perlu untuk di dikembangkan kembali.

3. Perlu untuk adanya pelatihan marketing untuk belajar bagaimana memasarkan dari hasilkreatifitas yang sudah dihasilkan.
4. Menjadi hal yang sangat mungkin dalam hal kewajiban dosen untuk melaksanakan tri dharma perguruan tinggi bagi dosen atas kewajibannya sebagai dosen untuk melakukan kegiatan PKM dan menjadikan Yayasan Pembangunan Masyarakat Sejahtera Kedaung Pamulang sebagai tempat binaan dosen dalam mengembangkan keilmuannya.

\section{Saran}

Mengadakan sosialisasi dan pelatihan serupa pada siswa sekolah lain di Kecamatan yang lain, dengan materi yang serupa. Adanya kesinambungan program pasca kegiatan pengabdian ini sehingga para siswa benar-benar dapat mengembangkan kemampuannya dalam berkreasi. Diadakannya kegiatan yang berkaitan dengan pemasaran produk yang sudah dihasilkan.

\section{DAFTAR PUSTAKA}

Hulasoh, E., Virby, S., \& Tilova, N. (2018). PENGENALAN KOSAKATA BAHASA INGGRIS MELALUI MEDIA STORYTELLING. Jurnal Pengabdian Dharma Laksana, 1(1), 101-110.

Qurbani, D., Oktrima, B., \& Tanjung, A. W. (2019). MENDIDIK DAN MENGAJARKAN ANAK UNTUK MENGENAL ALLAH PADA USIA DINI DENGAN METODE STORY TELLING DI TK AL-HIDAYAH PAMULANG, TANGERANG

SELATAN. Jurnal Pengabdian Dharma Laksana, 1(2), 228-239.

Pasaribu, V. L. D., Agrasadya, A., Shabrina, N., \& Krisnaldy, K. (2020). MENJADI ENTERPRENEUR MUDA YANG MEMILIKI JIWA LEADERSHIP UNTUK MENGHADAPI MASA DEPAN. Abdi Laksana, 1(1)

Pasaribu, V. L. D., Elburdah, R. P., Sudarso, E., \& Fauziah, G. (2020). PENGGUNAAN MANAJEMEN WAKTU TERHADAP PENINGKATAN PRESTASI BELAJAR DI SMP ARAISIYAH. Jurnal ABDIMAS, 1(1) 


\section{Loyalitas Kreativitas \\ Aldi Masyarakat Kreatif}

P-ISSN 2722-2101, E-ISSN 2722-4201

Program Studi Ekonomi Manajemen Universitas Pamulang Jurnal LOKABMAS Kreatif Vol. 01, No. 02, Hal. 56-61

Email:jurnalkreatif.manajemen@gmail.com
Pasaribu, V. L. D., Susanti, F., \& Hartuti, E. T. K. (2019). MEMOTIVASI SISWA DAN SISWI SMK LETRIS INDONESIA DI DALAM MENENTUKAN PILIHAN UNTUK MELANJUTKAN PENDIDIKAN ATAU BEKERJA SETELAH LULUS SEKOLAH. Jurnal Pengabdian Dharma Laksana, 1(2), 161-172.

Pasaribu, V. L. D., Oktrima, B., Prabowo, B., Arianto, N., \& Haryoko, U. B. (2020). PROGAM PENDAMPINGAN DAN

PENYELENGGARAAN PENDIDIKAN ANAK PADA USIA DINI TERHADAP PRESTASI BELAJAR DILINGKUNGAN RT 020 RW 009. KEL GIRI PENI. KEC WATES. YOGYAKARTA. JURNAL LOKABMAS KREATIF, 1(1), 71-75.

Pasaribu, V. L. D., Sulaiman, S., Sutiman, S., Thaharudin, T., \& Purnomo, B. Y. (2020). PENGENALAN LETAK POSYANDU TERDEKAT DIKELURAHAN PISANGAN DENGAN MANAJEMEN PEMASARAN REVOLUSI 4.0 UNTUK MENINGKATKAN PENGETAHUAN MASYARAKAT LETAK DAN FUNGSI POSYANDU TERDEKAT PADA KELURAHAN PISANGAN. DEDIKASI PKM, 1(1), 105-110.

Pasaribu, V. L. D., \& Krisnaldy, K. (2019). Manajemen Risiko dan Asuransi.

Purwanto. 2007. Instrumen Penelitian Sosial dan Pendidikan, Pengembangan dan Pemanfaatan. Yogyakarta: Pustaka Pelajar

Woolfolk, A.E. 1995. Educational Psychology. Boston : Allyn and Bacon.

W.S. Winkel. 1996. Psikologi Pengajaran. Jakarta: Gramedia.

Sunaryo. 2002. Psikologi Untuk Keperawatan. Jakarta: EGC.

Suryana. 2001. Kewirausahaan. Jakarta : Salemba Empat

\section{Peraturan Perundang-Undangan}

Undang-Undang No 19 Tahun 2002 Tentang Hak Cipta.

\section{DOKUMENTASI KEGIATAN}
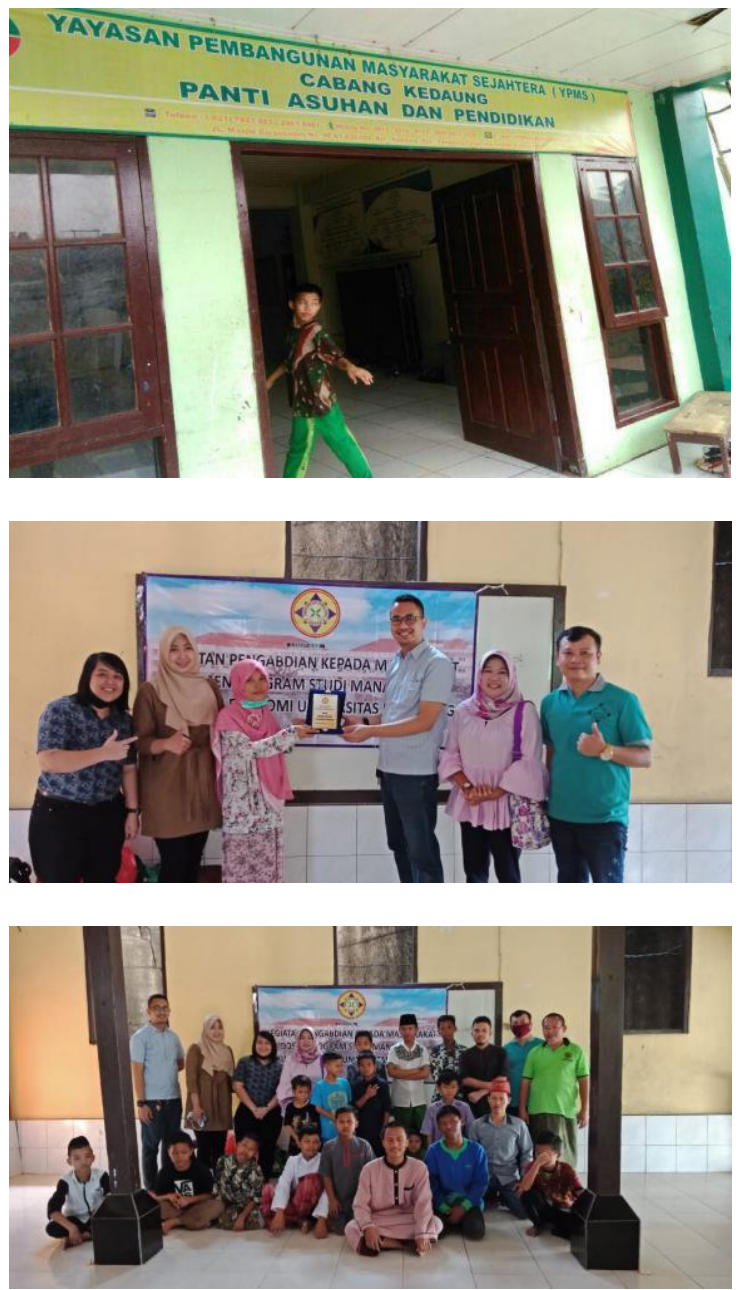